\title{
PERFORMANCE ANALYSIS OF INC BASED MPPT FOR PV SYSTEM
}

\author{
Gohil Sanjay Kantibhai ${ }^{1}$, Santosh Kumar ${ }^{2}$ \\ E-Mail Id: gohilsanjay13@gmail.com ${ }^{1}$, santosh_en@ rediffmail.com ${ }^{2}$ \\ Department of Electrical \& Electronics Engineering, Millennium Institute of Technology \& Science, Bhopal \\ (MP), India
}

\begin{abstract}
Due to increment of power demand here to find the new type of generation system. The concept of Renewable Energy Source (RES) is now become a most popular for generation of power. There are basically three types of RES is used for generation process, Wind, PV, fuel cell. Solar system is the one of the best RES techniques for generation of electrical power but it have some drawback. It is only used in the day time and has low efficiency. For improving the efficiency of the system here maximum power tracking is needed. Here in this paper discuss the Incremental Conduction based MPPT for tracking the solar power. The whole system is modelled in MATLAB software for checking the performance of the system.
\end{abstract}

Keywords- PV Module, MPPT, MPOP, P \& O, INC, MATLAB/ SIMULINK.

\section{INTRODUCTION}

The economic growth of a nation depends heavily on reliability and eminence of its electric power supply. Global energy demands are expected to grow by $60 \%$ over the next 25 years subjected to three significant factors; population growth, rate of gross domestic product (GDP) and energy intensification. This has the potential to cause a significant increase in GHG emissions associated with climate change. Secure, reliable and affordable energy sources are fundamental to economic stability and development. Rising energy demand poses a challenge to energy security given increased reliance on global energy markets. The electricity industry, in particular in the industrialized world, holds an important and pro-active role in providing solutions to security of supply and to reduction of GHG emissions with economically feasible solutions. Achieving this transition, the power industry has only increased several challenges for the power system. Innovative power system architectures at various level in power system involving both new technologies and new ways of managing the network to ensure a balance fluctuation in energy demand and supply are incorporated. In addition, RES which continued to cultivate strongly in all end-use segments, delivering close to $20 \%$ of global electricity supply in 2010 , and expected to procure $39 \%$ and $77 \%$ of the global power supply from all sources by 2030 and 2050 as per recent market policy. It will play an essential role in advancing development by improving the access of millions to energy, whilst helping ensure energy security, and mitigating the existential risk of climatic change by reducing emission.

In the near future, the demand for electric energy is expected to increase rapidly due to the global population growth and industrialization. This increase in the energy demand requires electric utilities to increase their generation. Recent studies predict that the world's net electricity generation is expected to rise from 17.3 trillion kilowatt-hours in 2005 to 24.4 trillion kilowatt-hours (an increase of 41\%) in 2015 and 33.3 trillion kilowatt-hours (an increase of $92.5 \%$ ) in 2030 [1]. Currently, a large share of electricity is generated from fossil fuels, especially coal due to its low prices. However, the increasing use of fossil fuels accounts for a significant portion of environmental pollution and greenhouse gas emissions, which are considered the main reason behind the global warming. For example, the emissions of carbon dioxide and mercury are expected to increase by $35 \%$ and $8 \%$, respectively, by the year 2020 due to the expected increase in electricity generation [2]. Moreover, possible depletion of fossil fuel reserves and unstable price of oil are two main concerns for industrialized countries.

To overcome the problems associated with generation of electricity from fossil fuels, renewable energy sources can be participated in the energy mix. One of the renewable energy sources that can be used for this purpose is the light received from the sun. This light can be converted to clean electricity through the photovoltaic process. The use of photovoltaic (PV) systems for electricity generation started in the seventies of the 20th century and is currently growing rapidly worldwide. In fact, many organizations expect a bright future for these systems. But there is a problem in using the PV system for generation process a bad efficiency of the system. The position of the sun is changes all time in day. So the output of the PV system get vary. For producing the high power here need of some tracking system which is known as Maximum Power Tracking System (MPPT). This is more beneficial for finding the point where maximum power achieve in the PV system,

In this paper discuss the different types of MPPT algorithm proposed by the researchers for increasing the efficiency of the solar system. Further a system model is developed based on INC MPPT algorithm. The whole model is developed in MATLAB software for checking the performance of the proposed system.

\section{REVIEW OF MPPT FOR PV SYSTEM}

The solar irradiance and temperature are dynamic. Hence an online algorithm which dynamically computes the operating point of the solar panel is required. The efficient conversion of solar energy is possible with Maximum Power Point Tracking (MPPT) algorithm. In his section discuss the different authors work in the field of MPPT. The 
Special Issue on Electrical System

International Journal of Technical Research \& Science (Special Issue) ISSN No.:2454-2024 (online)

author [1] discusses the method to track maximum power point for PV system. A high frequency PV for led acid battery is discussed in [2]. By The PV-PC implemented by a boost current converter (BCC) is to eliminate sulphating crystallization on the electrode plates of the LAB and to prolong the battery life. Hussein et.al [3] developed a new MPT algorithm to track maximum power operation point (MPOP) by comparing the incremental and instantaneous conduction of the PV array. A new method named CVT (Constant Voltage Tracking) is developed in [4]. In this paper a lower power PV system with simple structure has been designed. Noppadol et.al [5] present adjustable self-organised Fuzzy logic controller (SOFLC) for a solar power traffic ;light system. The P \& O method for MPPT is based on fuzzy system is designed in [6]. The introduction of artificial neural network based MPPT is developed in [7]. By applying a three layers neural network and some simple activation functions, the maximum power point of a solar array can be efficiently tracked. S. Yuvarajan et al [8] proposed a fast and accurate maximum power point tracking (MPPT) algorithm for a photovoltaic (PV) panel that uses the open circuit voltage and the short circuit current of the PV panel. Prof. Dr. IlhamiColak, et al [9] have modeled three separate solar farms that provide $15 \mathrm{~kW}$ power for each farm using Mat lab Simulink real-time analysis software. Energy conversion was performed with maximum power point tracking (MPPT) algorithms in each converter using Perturb and Observe (P\&O) structure. S. G. Tesfahunegn et al [10] designed a new solar/battery charge controller that combines both MPPT and over-voltage controls as single control function. A small-signal model of lead acid battery was derived in detail to design the employed dual-loop control configuration. Yuncong Jiang et.al [11] present an analogue Maximum Power Point Tracking (MPPT) controller for a Photovoltaic (PV) solar system that utilizes the load current to achieve maximum output power from the solar panel. Arash Shafie et al [12] proposed a novel MPPT algorithm mainly for battery charging applications which were considered constant voltage type loads. This was achieved mainly with output current maximization. This technique benefits from advantages such as very simple current controller and also circuit topology independency. Ali F Murtaza et al [13] addresses this problematic behavior of $\mathrm{P} \& \mathrm{O}$ technique and hence presents a novel MPPT hybrid technique that was combination of two basic techniques i.e. P\&O and Fractional Open Circuit Voltage (FOCV) technique in order to overcome the inherited deficiencies found in $\mathrm{P} \& \mathrm{O}$ technique. The proposed MPPT technique was much more robust in tracking the MPP even under the frequent changing irradiance conditions and was less oscillatory around the MPP as compared to $\mathrm{P} \& \mathrm{O}$. Weidong Xiao et al [14] introduce the performance analysis of photovoltaic modules in non-ideal conditions and the topologies to minimize the degradation of performance caused by these conditions. It was found that the peak power point of a module was significantly decreased due to only the slightest shading of the module, and that this effect was propagated through other non-shaded modules connected in series with the shaded one. Jun Pan et al [15] present according to the output characteristics of photovoltaic (PV) array and battery charging characteristics, design of a PV charging system with maximum power point tracking (MPPT). Sandeep Anand et al [16] proposed charged controller for limitation in battery life. They discuss in this paper in standalone dc system, dc-dc converter was used to interconnect solar photovoltaic (PV) and battery. To utilize solar PV to fullest, maximum power point tracking (MPPT) was incorporated in controller. Mohamed Azab [17] proposed a new maximum power point tracking algorithm for photovoltaic arrays. The algorithm detects the maximum power point of the PV. The computed maximum power was used as a reference value (set point) of the control system. ON/OFF power controller with hysteresis band was used to control the operation of a Buck chopper such that the PV module always operates at its maximum power computed from the MPPT algorithm. Ashish Pandey et al [18] describe about the limitations of Perturb \& Observe $(\mathrm{P} \& \mathrm{O})$ method because of continuously changing environmental conditions. A variable step-length algorithm was proposed and the drift was minimized by evaluating the entire trend in a power versus voltage curve Ahmed $\mathrm{k}$ et al.[19] proposed a high performance adaptive $\mathrm{P} \& \mathrm{O}$ based MPPT system. In this paper, a modified P\&O MPPT technique, applicable for PV systems, is presented. The proposed technique achieves: first, adaptive tracking; second, no steady-state oscillations around the MPP; and lastly, no need for predefined system-dependent constants, hence provides a generic design core. Y.Jiang et. al [20] present Adaptive Step Size With Adaptive-Perturbation Frequency Digital MPPT Controller for a Single-Sensor Photovoltaic Solar System. This paper presents a load-current-based maximum power point tracking (MPPT) digital controller with an adaptive step-size and adaptive-perturbation-frequency algorithm. Venkata Reddy et.al [21] present a Simple and Efficient MPPT Scheme for PV Module Using 2-Dimensional Lookup Table. In this paper proposes a simple and efficient MPPT scheme using a 2-Dimensional Lookup Table. Venketa Reddy Kota et al [22] present a novel linear tangents based P \& O scheme for MPPT of a PV system. In this paper first presents an overview on traditional Maximum Power Point Tracking (MPPT) algorithms. Traditional algorithm can be easily implemented using analog or digital devices. As traditional algorithms

suffer from low efficiency, oscillations in steady state power and poor dynamic performance, a novel MPPT scheme using Linear Tangents based Perturb \& Observe (LTP \& O) is proposed in this paper.

\section{INCREMENTAL CONDUCTION METHOD}

Incremental Conductance (INC) method is widely used MPPT technique. The disadvantage of P\&O method, of oscillation of operating point around MPP during changing environmental conditions can be reduced in INC method

by comparing the instantaneous panel conductance $\left(I_{P V} / V_{P V}\right)$ with the incremental panel conductance

DOI Number: https://doi.org/10.30780/specialissue-electrical system/003 $\quad$ pg. 18 Paper Id: IJTRS-ES-003

@ 2017, IJTRS All Right Reserved, www.ijtrs.com 
Special Issue on Electrical System

International Journal of Technical Research \& Science (Special Issue) ISSN No.:2454-2024 (online) $\left(d I_{P V} / d V_{P V}\right)$. The voltage of MPP is tracked to satisfy $\left(d P_{P V} / d V_{P V}\right)=0$, which is MPP. INC based algorithm is advantageous over other conventional methods because it is easy to implement, high tracking speed and better efficiency. Output power from solar panel is: $P_{P V}=P V$ array output power.

$$
\begin{aligned}
& P_{P V}=V_{P V} I_{P V} \\
& \frac{d P_{P V}}{d V_{P V}}=I_{P V}+V_{P V}\left(\frac{d I_{P V}}{d V_{P V}}\right)
\end{aligned}
$$

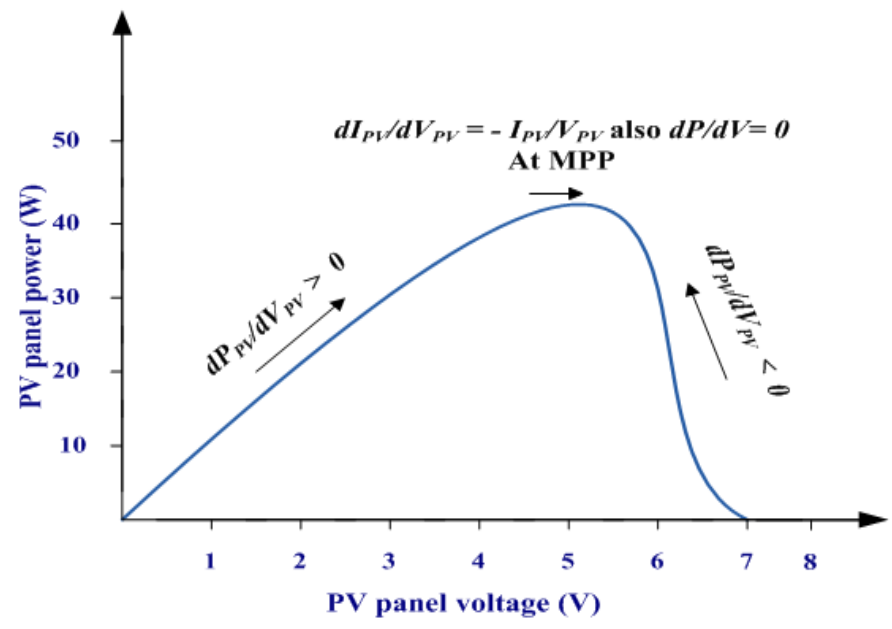

Fig. 3.1 PV Curve for INC MPPT

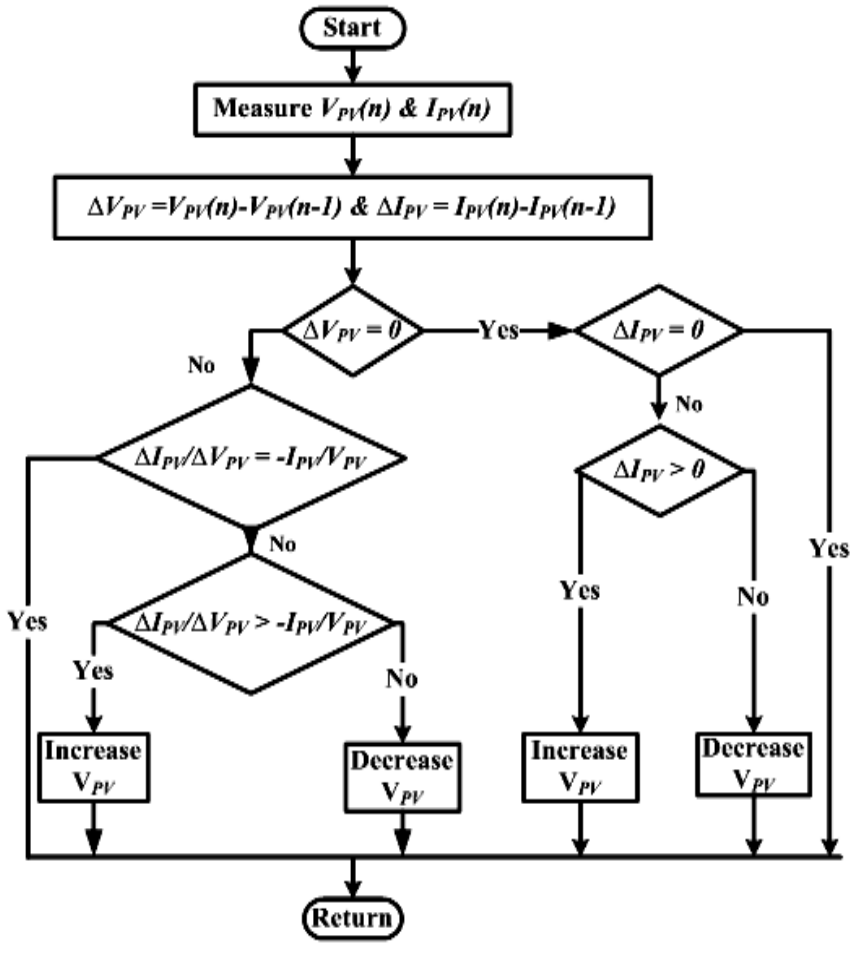

Fig. 3.2 Flow Chart of Proposed INC MPPT

From the PV curve at MPP

$$
\begin{aligned}
& \frac{d P_{P V}}{d V_{P V}}=0 \\
& \frac{d I_{P V}}{d V_{P V}}=-\frac{I_{P V}}{V_{P V}}
\end{aligned}
$$

If the operating point is on the right of the power curve then we have

$$
\frac{d P_{P V}}{d V_{P V}}<0
$$

If the operating point is on the left of the power curve then we have

$$
\frac{d P_{P V}}{d V_{P V}}<0
$$

In this algorithm the present and previous values of the solar panel voltage and current are sensed and are used to calculate the values of $d I_{P V}$ and $d V_{P V}$.

The algorithm is as shown in Fig.3.2 for voltage based Incremental Conductance MPPT, similar algorithm exists for current based control where current is sensed compared and changed.

If $d V_{P V}=0$ and $d I_{P V}=0$, MPP is reached for particular atmospheric condition and $\frac{d P_{P V}}{d V_{P V}}=0$ operating voltage is equal to maximum power point voltage for this atmospheric condition and is not changed further, that is there is no perturbation until a change in atmospheric conditions is sensed.

If $d V_{P V}=0$ and $d I_{P V}>0$, and amount of insolation increases, the PV power increases raising the MPP voltage. This requires the MPPT to increase the operating voltage to track the MPP.

On the other hand if $d I_{P V}<0$, decrease in insolation lowers the PV power and also lowering the MPP voltage and this requires the MPPT to decrease the PV array operating voltage. 
Special Issue on Electrical System

International Journal of Technical Research \& Science (Special Issue) ISSN No.:2454-2024 (online)

If $\frac{d I_{P V}}{d V_{P V}}>-\frac{I_{P V}}{V_{P V}}$, then $\frac{d P_{P V}}{d V_{P V}}>0$, and the PV array operating point is to the left of the MPP on the P-V curve.

Thus, the PV panel voltage is to be increased to reach the MPP.

Similarly, if $\frac{d I_{P V}}{d V_{P V}}<-\frac{I_{P V}}{V_{P V}}$, then $\frac{d P_{P V}}{d V_{P V}}<0$ and the PV panel operating point lie to the right of the MPP on the P-V curve and the voltage must be reduced to reach the MPP.

The duty cycle of the DC/DC converter is changed accordingly which changes the PV operating voltage to track the MPP. The problem of fixed small or large steps can be resolved, if MPPT with variable step size is used, where the algorithm changes the step size automatically according to the PV array characteristics as suggested in the Variable Step Size (Modified) INC MPPT algorithm.

\section{SIMULATION \& RESULTS ANALYSIS}

The whole system is modelled in MATLAB software. For modelling of the model here require mathematical expression. Figure 4.1 shows the Simulink model of proposed system.

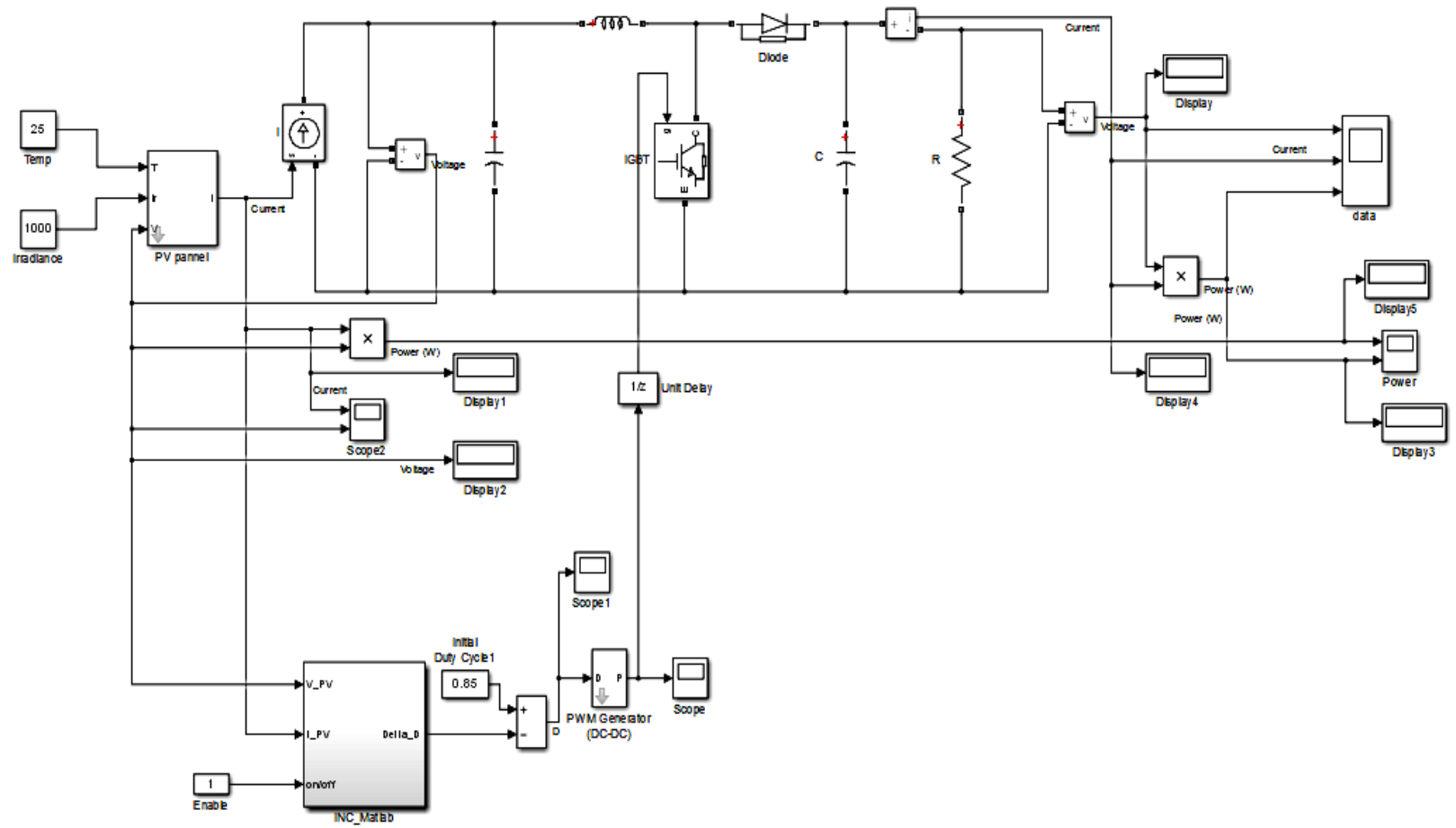

Fig. 4.1 SIMILINK Model of Proposed Work

From the figure 4.1 it is clearly shows that the output of the solar module is connected to the boost converter for DC to DC conversion. The MPPT algorithm here used in incremental \& Conduction based. For using INC method the output of the voltage and current is sensed by the current sensor and voltage sensor. This MPPT produce the pulse for on and off the switch used in the boost converter. In the next section discuss the brief of the model.

Table-4.1 Parameter Used in Simulation

\begin{tabular}{|l|c|}
\hline \multicolumn{1}{|c|}{ Parameter } & Value \\
\hline \multicolumn{1}{|c|}{ PV Module } \\
\hline Number of Series Connected Cell & 96 \\
\hline Open Circuit Voltage $\left(\mathrm{V}_{\mathrm{OC}}\right)$ & $64.2 \mathrm{~V}$ \\
\hline Short Circuit Current $\left(\mathrm{I}_{\mathrm{SC}}\right)$ & $5.96 \mathrm{~A}$ \\
\hline Series resistance & $0.18 \Omega$ \\
\hline Shunt Resistance & $360 \Omega$ \\
\hline Number of Module in Series & 2 \\
\hline Number of Module in Parallel & 2 \\
\hline
\end{tabular}

DOI Number: https://doi.org/10.30780/specialissue-electrical system/003 
Special Issue on Electrical System

International Journal of Technical Research \& Science (Special Issue) ISSN No.:2454-2024 (online)

\begin{tabular}{|l|c|}
\hline PV Side Capacitance & $470 \mu \mathrm{F}$ \\
\hline \multicolumn{2}{|c|}{ Boost Converter } \\
\hline Series Inductance & $10 \mathrm{mH}$ \\
\hline Shunt Capacitance & $47 \mu \mathrm{F}$ \\
\hline Load Resistance & $100 \Omega$ \\
\hline
\end{tabular}

Table 4.1: show the parameter used in the simulation of the proposed work.

Fig. 4.2 to fig. 4.7 shows the output current, voltage and power of to the proposed PV module respectively. And fig. 4.5 to fig. 4.7 shows the output current, voltage and power with the application of INC MPPT in PV module.

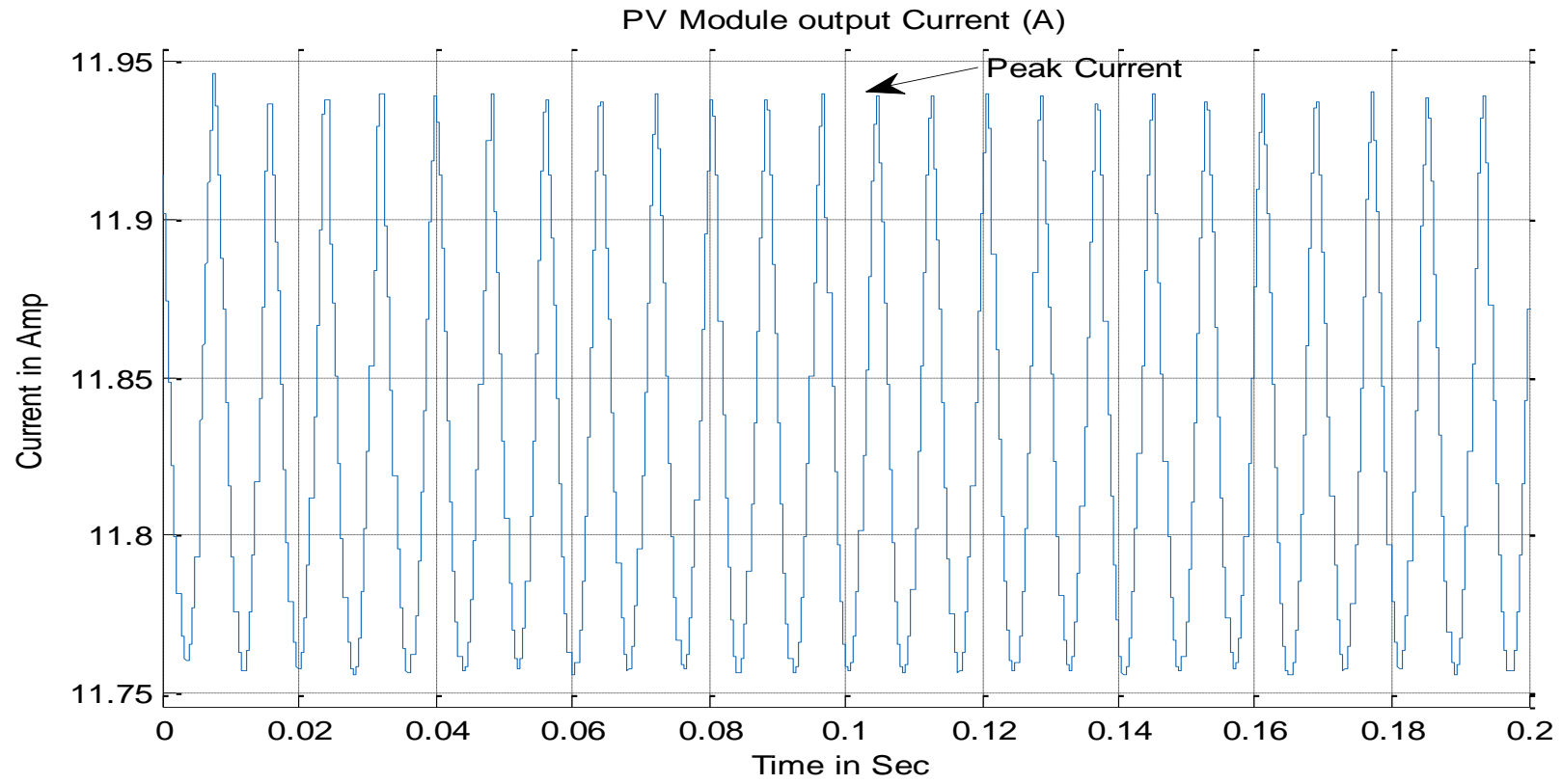

Fig. 4.2 Current Output of Proposed PV Module

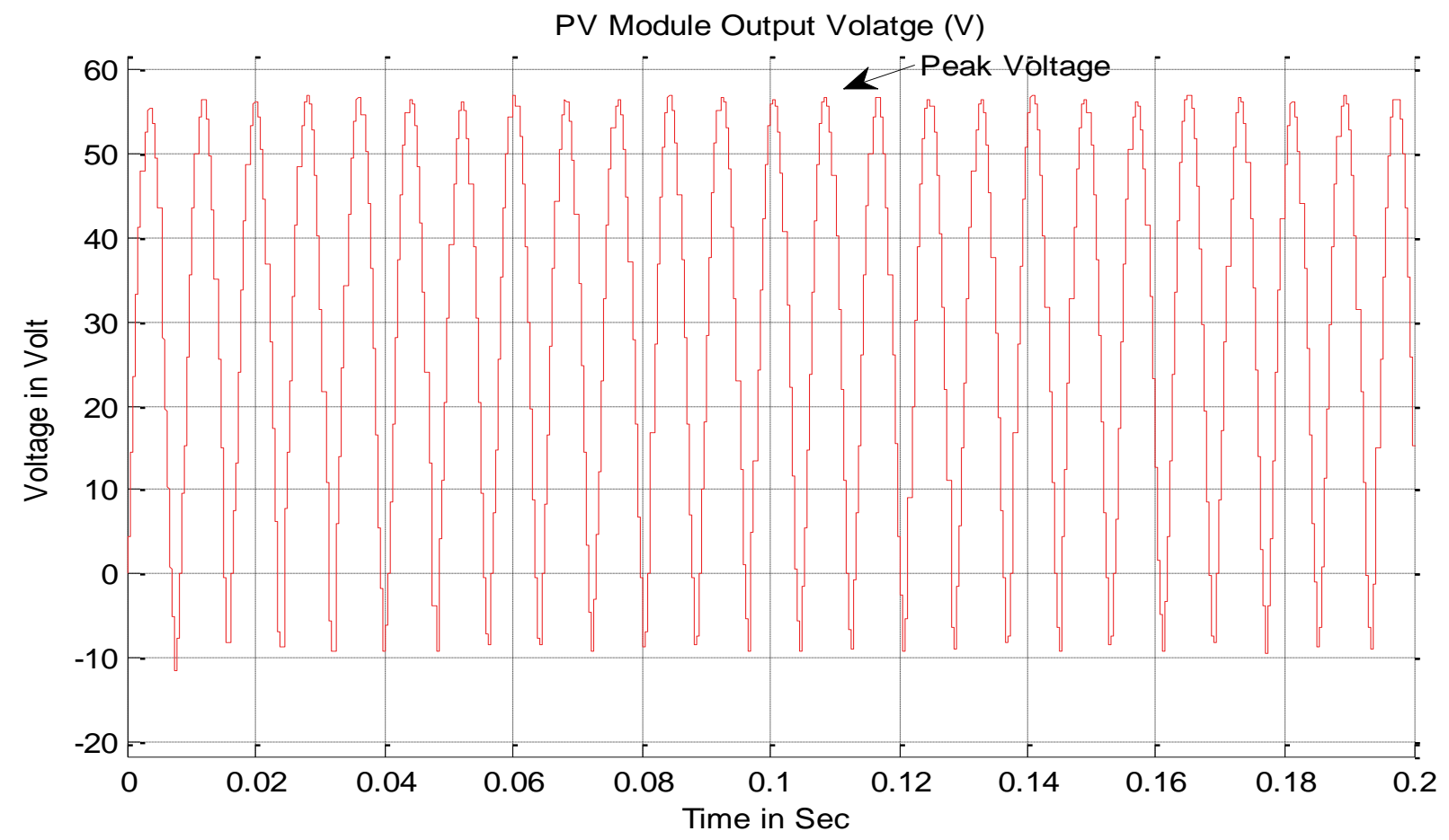

Fig. 4.3 Voltage Output of Proposed PV Module

DOI Number: https://doi.org/10.30780/specialissue-electrical system/003 Paper Id: IJTRS-ES-003

@ 2017, IJTRS All Right Reserved, www.ijtrs.com 
Special Issue on Electrical System

International Journal of Technical Research \& Science (Special Issue) ISSN No.:2454-2024 (online) PV Module Output Power $\left(\mathrm{W}_{\mathrm{P}}\right)$

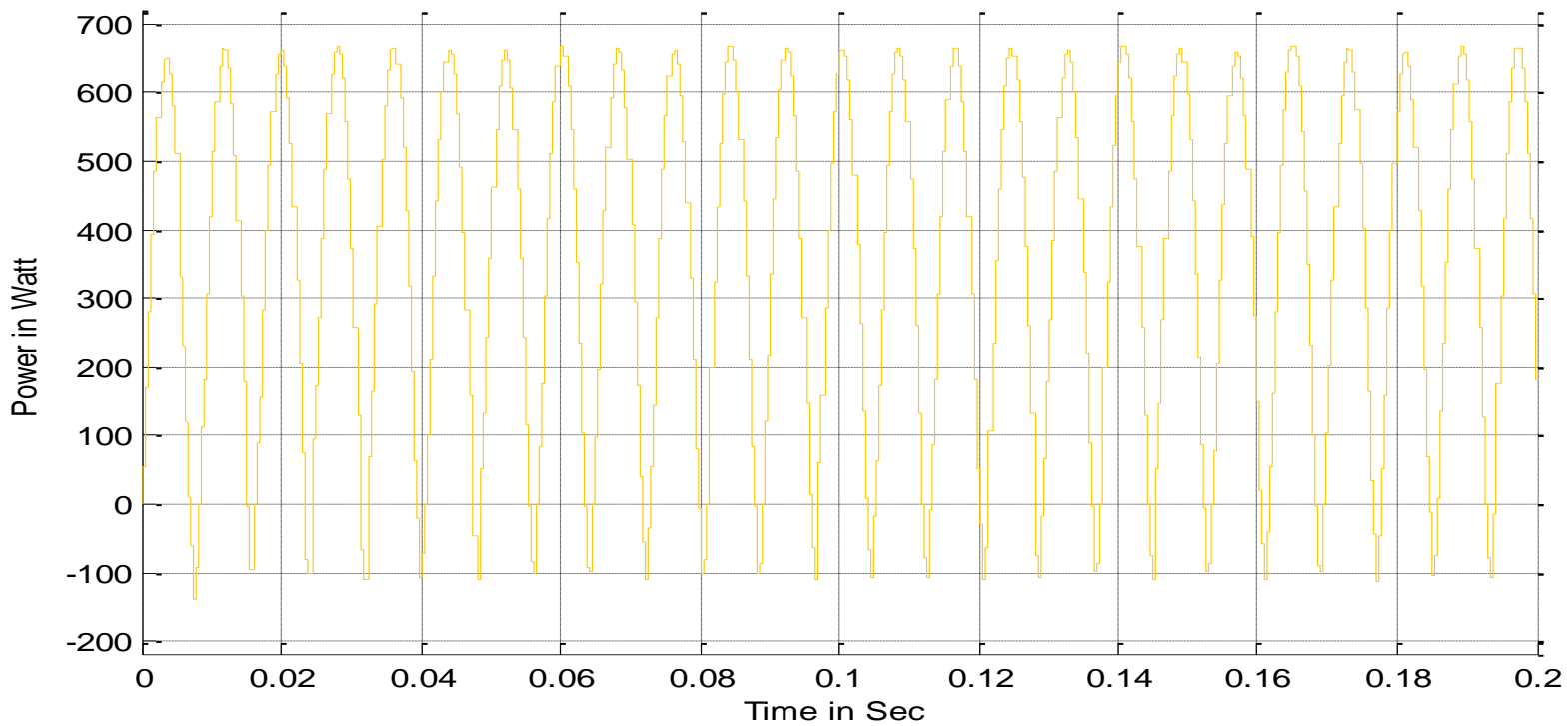

Fig. 4.4 Power Output of Proposed PV Module

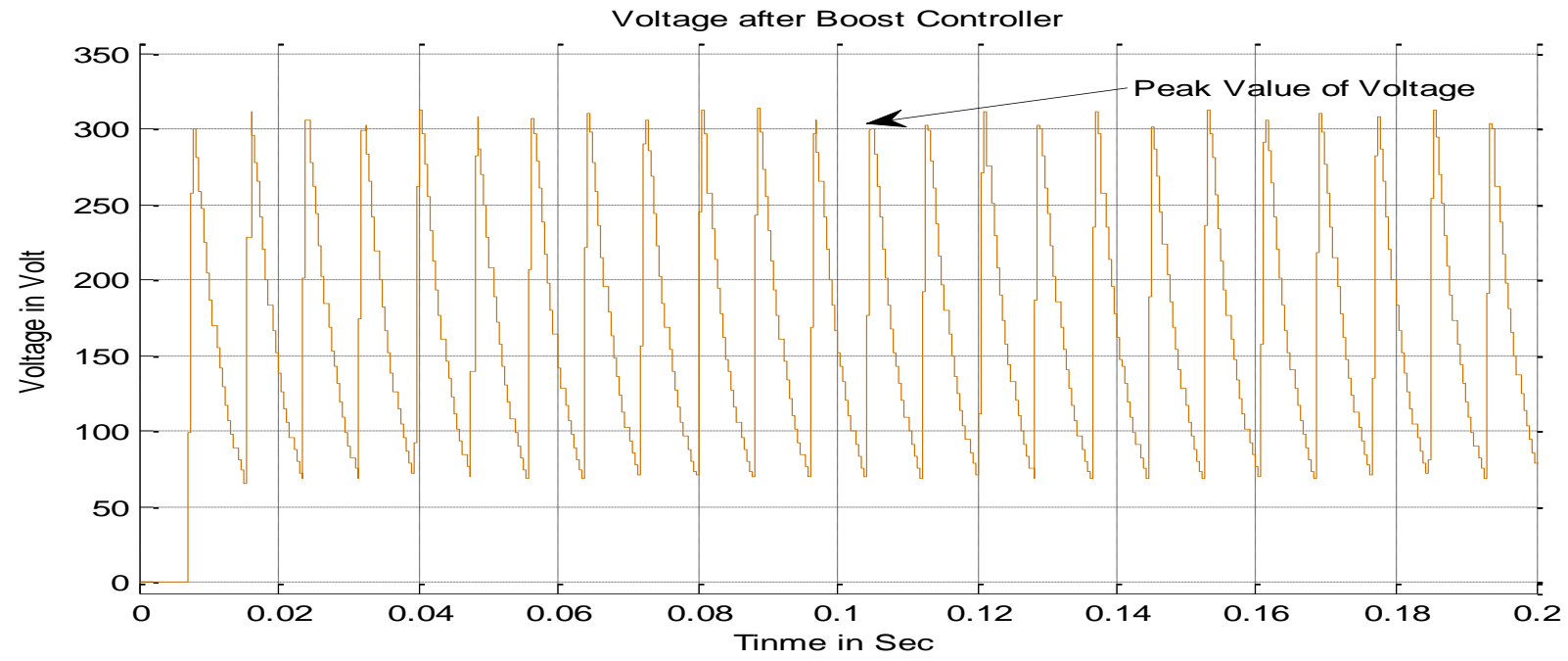

Fig. 4.5 Current Output After INC MPPT Based Boost Converter

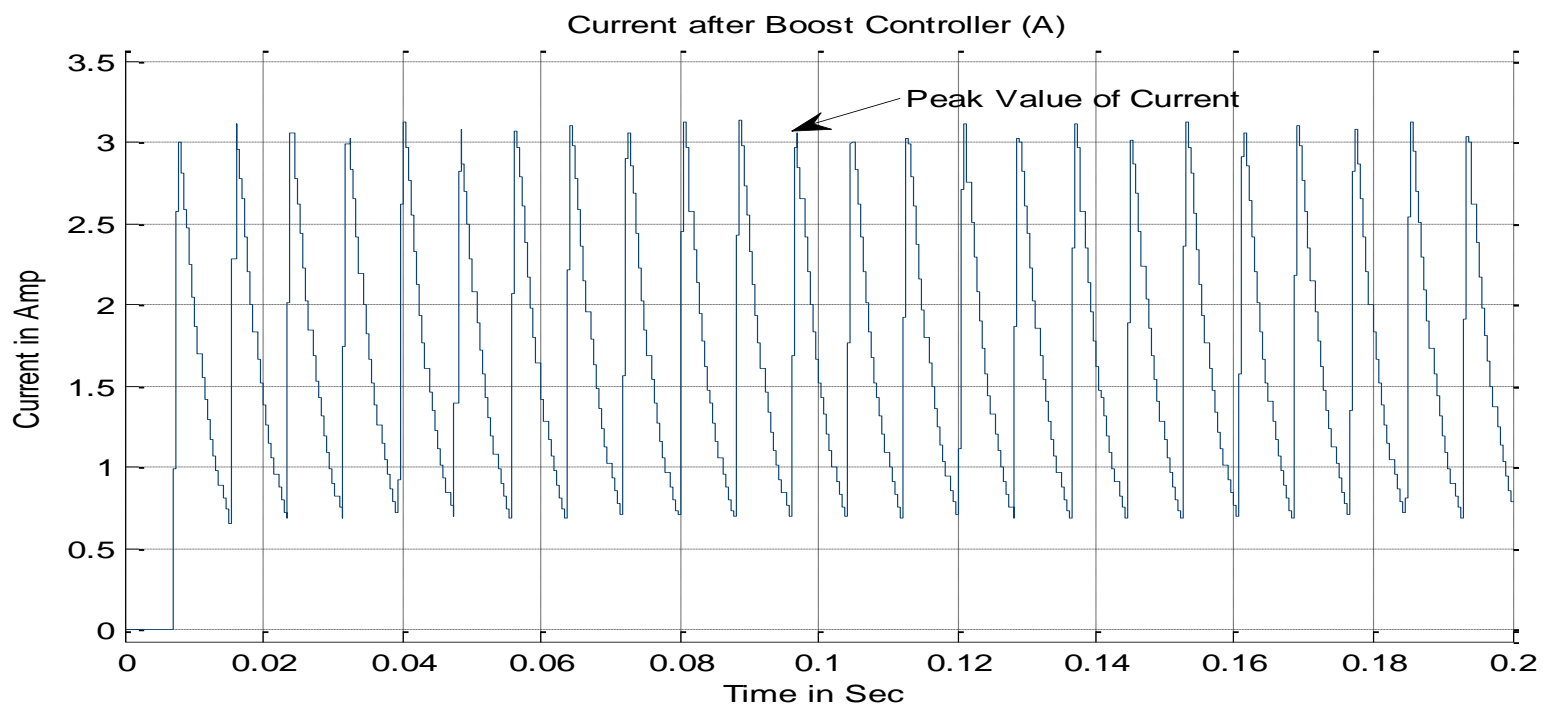

Fig. 4.6 Voltage Output After INC MPPT Based Boost Converter

DOI Number: https://doi.org/10.30780/specialissue-electrical system/003 


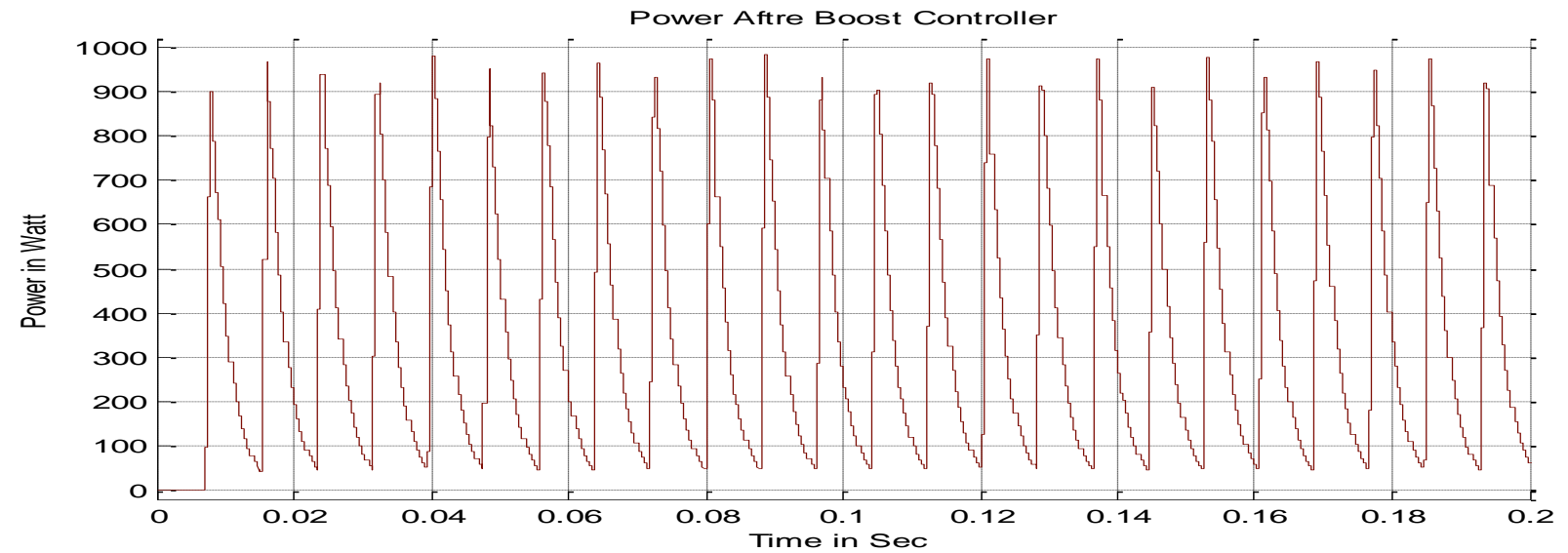

Fig. 4.7 Power Output After INC MPPT Based Boost Converter

\section{CONCLUSION}

Maximum power tracking system is become important in the field of PV generation. Due to rapid growth of the PV generation system here focus on the MPPT. MPPT algorithm is used for finding the maximum power of the PV system in day time. Conventionally there is used P \& O algorithm for tracking the MPP. But this method has some limitation that's why a new methodology needs to implemented in tracking MPP. On the basis of here in this paper discuss a Incremental Conduction based Maximum Power Tracking scheme. The proposed work is implemented in MATLAB software for checking the performance of the system.

\section{REFERENCES}

[1] TrishanEsram and Patrick L.Chapman, "Comparison of Photovoltaic Array Maximum Power Point Tracking Techniques,"IEEE Transactions on Energy Conversion, Vol. 22, No. 2, June 2007.

[2] Hung-I Hsieh, Jen-Hao Hsieh, et al., "A Study of High-Frequency Photovoltaic Pulse Charger for Lead-Acid Battery Guided by PI-INC MPPT".

[3] K.H. Hussein, I. Muta, T. Hoshino and M. Osakada, "Maximum photovoltaic power tracking:an algorithm for rapidly changing atmospheric conditions," IEEEploc.-Gener. Transmission and Distribution, Vol. 142, No. 1 , Jan. 1955.

[4] C.Thulasiyammal and S Sutha, "An Efficient Method of MPPT Tracking System of a Solar Powered Uninterruptible Power Supply Application,” 1st International Conference on Electrical Energy Systems, 2011.

[5] NoppadolKhaehintung and PhaophakSirisuk, "Application of Maximum Power Point Tracker with Selforganizing Fuzzy Logic Controller for Solar powered Traffic Lights,” IEEE, 2007.

[6] C. S. Chin, P. Neelakantan, et al., "Fuzzy Logic Based MPPT for Photovoltaic Modules Influenced by Solar Irradiation and Cell Temperature," UKSim 13th International Conference on Modelling and Simulation, 2011.

[7] PanomPetchjatuporn, PhaophakSirisuk, et al., "A Solar-powered Battery Charger with Neural Network Maximum Power Point Tracking Implemented on a Low-Cost PIC-microcontroller".

[8] S. Yuvarajan and JulineShoeb, "A Fast and Accurate Maximum Power Point Tracker for PV Systems," IEEE, 2008.

[9] Prof.Dr.IlhamiColak, Dr.ErsanKabalci and Prof.Dr.GungorBal, "Parallel DCAC onversion System Based on Separate Solar Farms with MPPT Control," 8th International Conference on Power Electronics - ECCE Asia, The ShillaJeju, Korea, May 30-June 3, 2011.

[10] S. G. Tesfahunegn, O. Ulleberg, et al., "A simplified battery charge controller for safety and increased utilization in standalone PV applications," IEEE, 2011.

[11] Yuncong Jiang, Ahmed Hassan, EmadAbdelkarem and Mohamed Orabi, "Load Current Based Analog MPPT Controller for PV Solar Systems," IEEE, 2012.

[12] ArashShafiei, AhmadrezaMomeni and Sheldon S. Williamson, "A Novel Photovoltaic Maximum Power Point Tracker for Battery Charging Applications," IEEE, 2012.

[13] Ali F Murtaza, Hadeed Ahmed Sher, et al., "A Novel Hybrid MPPT Technique for Solar PV Applications Using Perturb \& Observe and Fractional Open Circuit Voltage Techniques".

[14] Weidong Xiao, Nathan Ozog and William G. Dunford, "Topology Study of Photovoltaic Interface for Maximum Power Point Tracking,’'IEEE Transactions on Industrial Electronics, Vol. 54, No. 3, June 2007.

[15] Jun Pan, Chenghua Wang and Feng Hong, "Research of Photovoltaic Charging System with Maximum Power Point Tracking," The Ninth International Conference on Electronic Measurement \& Instruments ICEMI, 2009.

DOI Number: https://doi.org/10.30780/specialissue-electrical system/003 Paper Id: IJTRS-ES-003

pg. 23 
International Journal of Technical Research \& Science (Special Issue) ISSN No.:2454-2024 (online)

[16] Sandeep Anand, Rajesh Singh Farswan, et al., "Optimal Charging of Battery Using Solar PV in Standalone DC System".

[17] Mohamed Azab, "A New Maximum Power Point Tracking for Photovoltaic Systems," International Journal of Electrical and Electronics Engineering 3:11, 2009.

[18] Ashish Pandey, NiveditaDasgupta and Ashok Kumar Mukerjee, "HighPerformance Algorithms for Drift Avoidance and Fast Tracking in Solar MPPT System," IEEE Transactions on Energy Conversion, Vol. 23, No. 2, June 2008.

[19] Ahmed K. Abdelsalam, Ahmed M. Massoud, Shehab Ahmed, and Prasad N. Enjeti,, "High-Performance Adaptive Perturb and Observe MPPT Technique for Photovoltaic-Based Microgrids", IEEE transactions on power electronics, vol. 26, no. 4, april 2011.

[20] Yuncong Jiang, Jaber A. Abu Qahouq, and Tim A. Haskew, "Adaptive Step Size With Adaptive-Perturbation Frequency Digital MPPT Controller for a Single-Sensor Photovoltaic Solar System", IEEE transactions on power electronics, vol. 28, no. 7, july 2013

[21] Venketa Reddy Kota and Muralidhar Nayak Bhukya, "A Simple and Efficient MPPT Scheme for PV Module Using 2-Dimensional Lookup Table" IEEE transaction of Poweer System 2016.

[22] Venkata Reddy Kota, Muralidhar Nayak Bhukya, "A novel linear tangents based P \& O scheme for MPPT of a PV system”, Renewable and Sustainable Energy Reviews, ELSEVIER 2017. 